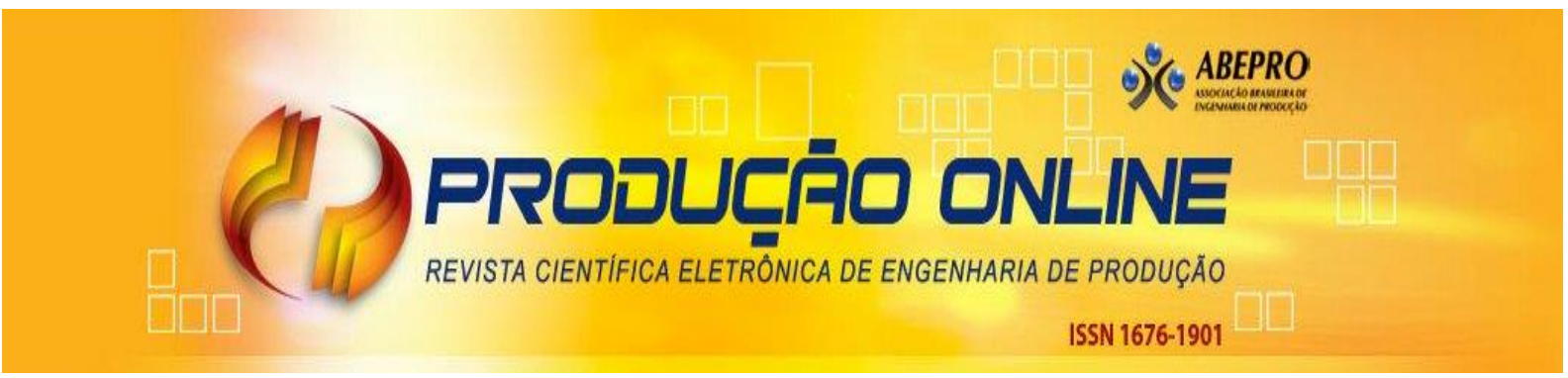

\title{
DESENVOLVIMENTO DA AET QUANDO O TRABALHO PRESCRITO NÃO ESTÁ CLARO: O CASO DE UMA INDÚSTRIA ALIMENTÍCIA
}

\section{DEVELOPMENT OF ERGONOMIC WORK ANALYSIS WHEN PRESCRIBED WORK IS NOT CLEAR: THE CASE OF A FOOD INDUSTRY}

\author{
Ingrid Losekan* E-mail: ingrilosekan@gmail.com \\ Joice Priscila Silveira Dias* E-mail: joice.priscila.dias@gmail.com \\ Corintha da Trindade Dias Neta* E-mail: corintha.diasneta@gmail.com \\ Juliano Ramires de Moraes Bagiotto* E-mail: julianobagiotto@gmail.com \\ Luis Antonio dos Santos Franz* E-mail: luisfranz@gmail.com \\ *Universidade Federal de Pelotas (UFPel), Pelotas, RS.
}

Resumo: A Ergonomia vem ganhando forte atenção por sua importância, ao permitir compreender e atuar na lacuna entre o trabalho prescrito e o real. Para isso, difundiu-se no Brasil um modelo de Análise Ergonômica do Trabalho (AET) dividida em cinco etapas principais, sendo elas a análise da demanda, a análise da tarefa, a análise da atividade, o diagnóstico e as recomendações ergonômicas, embora nem sempre a distinção entre o trabalho prescrito e real seja identificável. Neste contexto, o presente trabalho objetiva demonstrar a realização de uma Análise Ergonômica do Trabalho (AET) em uma empresa de médio porte que atua na produção de flocos de arroz e de cereais na região sul do RS, em um contexto onde o trabalho prescrito e o trabalho real não estão claramente separados. Para tanto, explora-se os caminhos de implantação de uma AET desde a identificação da demanda até a implantação de melhorias, apresentando-se ao final um olhar crítico a partir da vivência no cenário apresentado. Os resultados permitiram identificar que a AET pode trazer oportunidades importantes se implementada longitudinalmente e com os devidos cuidados de observação, diálogo e análise das operações, ainda que não exista um limite claro entre o trabalho prescrito e o trabalho real.

Palavras-chave: Análise Ergonomica do Trabalho. Análise de posturas. Indústria de alimentos. RULA. $\mathrm{NIOSH}$.

\begin{abstract}
Ergonomics has been gaining strong attention for its importance, helping to understand and act in the gap between prescribed and real work. In Brazil, a five-step Ergonomic Task Analysis (ETA) model was disseminated, namely, demand analysis, task analysis, activity analysis, diagnosis and ergonomic recommendations, although not always the distinction between the prescribed and real work is clear. In this context, the present work aims to demonstrate the implementation of an ETA in a medium-sized company that operates in the production of rice flakes and cereals in southern Brazil, in a context where the separation between the prescribed and real work is unclear. To this end, it explores the ways of implementation an ETA, from the identification of demand to the implementation of improvements, presenting at the end a critical view from the experience in the presented scenario. The results allowed us to identify that ETA can bring important opportunities if implemented longitudinally and with the proper care of observation, dialogue and analysis of operations, although there is no clear boundary between prescribed and actual work.
\end{abstract}

Keywords: Ergonomic task analysis. Posture analysis. Food industry. RULA. NIOSH. 


\section{INTRODUÇÃO}

A indústria de alimentos vem se destacando ao longo das últimas décadas, representando uma parcela significativa do PIB nacional. De acordo com dados da Associação Brasileira das Indústrias da Alimentação (ABIA), o Brasil ocupava em 2010 a sétima posição entre os principais exportadores mundiais de alimentos no que se refere apenas aos alimentos processados (COSTA e BRAGA, 2015). Contudo, este também é um dos principais setores com destaque em número de acidentes de trabalho no país, tendo registrado somente em 2015 núemros da ordem de 612,6 mil casos (APES, 2015).

Diante disso, torna-se imprescindível que ações para segurança dos trabalhadores também evoluam, de modo a incorporar novas ferramentas que possibilitem aos seus gestores o desenho de um ambiente institucional adequado para esse setor. Uma das alternativas para essa evolução é a aplicação de normas e regras ditadas pela Ergonomia (VICENZI et al., 2012).

A Ergonomia vem ganhando forte atenção por sua importância, ao compreender e atuar na lacuna entre o trabalho prescrito e o real. Por conta disso, ela mostra que para os trabalhadores as condicionantes físico-ambientais e organizacionais, muitas vezes, exigem uma representação mental diferenciada a cada dia (novas preparações, imprevisibilidade, novas pressões temporais, etc.), o que nem sempre é previsto na fase do planejamento da operações e processos (MONTEIRO, 2010). Infelizmente, a distinção entre o trabalho prescrito e o real é muitas vezes difícil de identificar, senão impraticável, obrigando os profissionais que realizam a Análise Ergonômica do Trabalho (AET) a implementá-la em um contexto em que a tarefa e a atividade confundam-se.

Dessa forma, o presente trabalho tem como objetivo demonstrar a realização de uma Análise Ergonômica do Trabalho (AET) em uma empresa de médio porte que atua na produção de flocos de arroz e de cereais na região sul do RS, em um contexto onde os trabalho prescrito e o trabalho real não estão claramente separados.

\section{REVISÃO BIBLIOGRÁFICA}

A partir de meados da década de 70 os negócios passaram a considerar ações com foco na produtividade sendo fortemente influenciadas por aspectos relativos à valorização da qualidade de vida da mão de obra envolvida nos processos de produção. 
Desde então, verificou-se um crescimento nas medidas para satisfazer as necessidades dos trabalhadores, já que o aumento da produtividade tornou-se claramente associado ao nível de bem-estar e à segurança dos trabalhadores (BATALHA, 2012).

\subsection{Indústria de alimentos e os riscos ocupacionais}

As empresas do setor alimentício brasileiro estão expostas a um contexto de alta competitividade e decorrente exigência de políticas de produtividade e competitividade. Por conta disso, elas acabam transferindo aos trabalhadores rotinas que levam a execução de tarefas repetitivas, acompanhadas de ruído, equipamentos perigosos, esforço físico intenso, entre outras exigências as quais o trabalho os submete (CASTRO et al., 2016). Dentre os principais acidentes observados neste cenário, destacam-se prensagem e agarramento de partes do corpo, lesões cortantes em mãos e braços, choques elétricos, queimaduras provocadas por vapor, água quente e produtos químicos. Na maioria dos casos ocorre o envolvimento do uso e operação de máquinas e equipamentos (SESI, 2008).

$\mathrm{Na}$ verdade, a indústria da alimentação de um modo geral opera por meio de processos que combinam atividades estritamente manuais com processos automatizados, tornando recorrente e grande a participação do trabalho manual no processamento. Como não bastasse isso, muitas dessas atividades são extremamente repetitivas, monótonas e realizadas em ritmos intensos. Pode-se inferir que essas atividades, realizadas em condições extremamente penosas,explicam por exemplo, a alta incidência de Lesões por Esforços Repetitivos (LER) no setor (SATO et al., 2000).

Para além daqueles riscos mais associados à demandas físicas, atualmente, identificam-se entre os trabalhadores ocorrência de acidentes provocados por pressões de trabalho, sendo que estes casos são particularmente críticos entre trabalhadores das indústrias de alimentos cujas atividades demandam cuidados acentuados em relação ao controle dos produtos, podendo acarretar-lhes desgastes emocionais, físicos e psicológicos. Tais aspectos podem influenciar diretamente no ritmo da produção, seja pela incidência de doenças psicológicas ou ainda, pela própria ocorrência de acidentes (RODRIGUES et al., 2008).

Tal cenário aponta para a importância das empresas não só se manterem provedoras de um ambiente seguro para os funcionários, mas ainda de poderem estar 
preparadas para o caso de eventuais visitas dos órgãos fiscalizadores, principalmente no caso daquelas realizadas pelos órgãos fiscalizadores regionais subordinados à Subsecretaria de Inspeção do Trabalho (SIT).

\subsection{Análise Ergonômica do Trabalho}

Conforme as condições em que as atividades são desempenhadas e de acordo com o tempo que o homem permanece em determina posição, realizando suas atividades, é possível que ocorram problemas como desconforto e fadiga (CORRÊA; BOLETTI, 2015). Para estas situações aplica-se a Ergonomia, que segundo lida e Guimarães (2016), tem como objetivo estudar os fatores que interferem no desempenho dos sistemas produtivos, minimizando as consequências negativas geradas ao trabalhador. Estes objetivos são alcançados pelo estudo da adaptação do trabalho às características dos indivíduos, proporcionando-Ihes o máximo de conforto, segurança e bom desempenho de suas atividades no trabalho. A Ergonomia é inclusive, considerada por alguns autores como uma ciência, a qual pesquisa, estuda e aplica regras e normas, a fim de tornar o trabalho compatível com as características físicas e psíquicas do ser humano (MORAES, 2014).

Um caminho que auxilia na compreensão e estabelecimento do bem estar dos trabalhadores em seus postos de trabalhos consiste na realização da Análise Ergonômica do Trabalho (AET). Esta utiliza-se dos conhecimentos da Ergonomia para analisar, diagnosticar e corrigir situações reais de trabalho (IIDA e GUIMARÃES, 2016). A AET, que no Brasil é prevista na Norma Regulamentadora № 17 (BRASIL, 2018), tem suas origens metodológicas na escola francesa e pode ser dividida em cinco etapas principais, sendo elas a análise da demanda, a análise da tarefa, a análise da atividade, o diagnóstico e as recomendações ergonômicas (GUERIN, 2001).

Contudo, a análise da tarefa e da atividade recorrentemente são prejudicadas pelo fato de as empresas contarem somente com um modo operacional não formalizado em seus processos. Ainda assim, a realização da AET continuará a depender de uma ampla gama de possibilidades de ferramentas e métodos. A escolha da melhor ferramenta varia de acordo com o objetivo do avaliador, com as características do posto de trabalho analisado e com as características das atividades nele presentes. 
Dentre os aspectos que costumam vir à tona como críticos e demandantes de análise durante a aplicação de uma AET, as posturas empregadas durante a atividade frequentemente ganham destaque. Ao verificar-se na literatura da área encontra-se diversas propostas de técnicas de análise, dentre as quais o Método RULA (MCATAMNEY; CORLETT, 1993), a equação de NIOSH (WATERS, 1994) e o método Strain Index (MOORE; GARG, 1995) configuram-se exemplos bons e recorrentes de métodos utilizados.

O método RULA avalia a postura do pescoço, tronco, membros superiores, membros inferiores, o esforço muscular e a carga sobre o corpo. Para a aplicação do método RULA, deve-se utilizar diagramas de postura e tabelas contendo scores, os quais auxiliam na atribuição de valores de acordo com a exposição do membro analisado a fatores de riscos ergonômicos. Os resultados obtidos pelo RULA referem-se ao tempo de ciclo observado e não ao tempo de jornada total (McATAMNEY; CORLETT, 1993).

Nos postos de trabalho que envolvem levantamento de cargas, pode ser utilizada a Equação de NIOSH, que é baseada em um modelo multiplicativo o qual confere um Peso Limite Recomendável (PLR) tomando como referência seis variáveis presentes em uma tarefa sendo elas a distância horizontal $(\mathrm{H})$, a distância vertical $(\mathrm{V})$, a distância vertical percorrida pela carga (D), o ângulo de assimetria (A), a frequência de levantamento $(F)$ e pega $(P)$. Os valores destas variáveis, obtidos conforme orientado na Figura 1 são inseridos em na equação 1, de forma a obter o PLR (WATERS, 1994).

Figura 1 - Variáveis utilizadas durante a aplicação da equação de NIOSH

LC: carga constante $=23 \mathrm{Kg}$
$\mathrm{HM}$ : multiplicador horizontal $=(25 / \mathrm{H})$
$\mathrm{VM}$ : multiplicador vertical $=\left(1-\left(0,003^{*}|\mathrm{~V}-75|\right)\right)$
$\mathrm{DM}$ : multiplicador distância $=(0,82+(4,5 / \mathrm{D}))$
$\mathrm{AM}:$ multiplicador assimetria $=(1-(0,0032 \times \mathrm{A}))$
$\mathrm{FM}:$ multiplicador frequência $=$ Extraído de uma
tabela
$\mathrm{CM}:$ multiplicador interface $=$ Extraído de uma tabela
$\mathrm{PLR}=\mathrm{LC} \times \mathrm{HM} \times \mathrm{VM} \times \mathrm{DM} \times \mathrm{AM} \times \mathrm{FM} \times \mathrm{CM}$

Fonte - Adaptado de lida e Guimarães, (2016)

O método Strain Index, por sua vez, mensura seis variáveis: Fator de Intensidade do Esforço (FIE), Fator de Duração do Esforço por ciclo de trabalho (FDE), Fator de Frequência do Esforço por minuto (FFE), Fator de Postura de Mão/Pulso (FPMP), Fator 
de Velocidade de Execução da tarefa (FVE) e Fator de Duração da Tarefa por dia (FDT). Para cada uma das variáveis é atribuído um score de acordo com o nível de riscos identificado para a variável. O índice de risco final fornecido pelo Strain Index é obtido pela multiplicação simples dos scores identificados para cada variável. Com isso podese obter três níveis de risco, sendo eles o Risco Baixo (valores abaixo de 3,0), Risco Intermediário (valores entre 3,0 e 7,0) e Risco Elevado (valor final acima de 7,0) (MOORE; GARG, 1995).

A aplicação de ambos os métodos exige observação atenta do analista, assim como o registro de alguns dados prévios, os quais podem envolver coleta de imagens ou coleta de medidas in loco.

\section{METODOLOGIA}

Uma das formas que mais se disseminou para AET é aquela proposta inicialmente pela escola francesa, através dos autores Guérin, Laville, Daniellou, Duraffourg e Kerguelen (2001). Essa abordagem possibilita idas e vindas dentro do processo de intervenção, ou seja, não precisa ser seguida de uma maneira sequencial (COELHO, 2014). No Brasil, a Norma Regulamentadora № 17 (NR-17), do Ministério do Trabalho e Emprego (BRASIL, 2018) foi bastante influenciada pelo que, na época, era chamado de ergonomia francofônica e que era nada menos, do que a ergonomia que estava sendo desenvolvida no então Laboratório de Ergonomia, do prestigiado Conservatório Nacional de Artes e Ofícios (CNAM), em Paris (FERREIRA, 2015).

Santos e Fialho (1997) colocam que a AET compreende três fases principais: análise da demanda, análise da tarefa e análise das atividades. Na análise da demanda define-se o problema a ser investigado com os atores envolvidos. A análise da tarefa coloca o que o trabalhador deve realizar e as condições ambientais técnicas e organizacionais. $\mathrm{E}$ a análise das atividades traz efetivamente o que é realizado pelo trabalhador, o comportamento do homem no trabalho. Destas fases, conforme demonstra Deimling (2014), deve emergir informações que permitam aos ergonomistas formular subjeções e hipóteses quanto às demandas presentes no local analisado.

O presente trabalho expõe o caso de implantação de uma AET em um contexto onde a tarefa confunde-se com a atividade, o que implica em desafios adicionais ao analista. Para tanto, explora-se o passo-a-passo da implantação da AET desde a 
identificação da demanda até a implantação de melhorias. Ao final, apresenta-se um olhar crítico a partir da vivência no cenário apresentado.

\section{RESULTADOS E DISCUSSÃO}

\subsection{Identificação/qualificação das demandas ergonômicas no local objeto de estudo}

A empresa abrangida no presente trabalho atua na produção de flocos de arroz e cereais, sendo que seus produtos chegam a diversas regiões do país por meio um modelo de coprodução, onde a responsabilidade pela produção de um produto ou serviço é compartilhada. A demanda ergonômica prioritária no setor de produção da empresa objeto de estudo foi identificada através de visitas e observação nas instalações da empresa por um especialista e discussão junto aos gestores da empresa. Considerando a diversidade de postos de trabalho no ambiente ocupacional em questão e as discussões realizadas, mostrou-se como prioritária a análise de alguns postos de trabalho, dentre os quais, aqueles que pertencem ao Setor de Cobertura se revelaram os mais expostos aos agentes ergonômicos. Neste setor passam produtos semiacabados destinados a receber o banho de um xarope, composto por elementos como água, açúcar cristal e carbonatos.

Dentre as possíveis aplicações deste banho de xarope pode ser citado o caso de cereais, os quais adquirem ao final do processo uma película de textura crocante e sabor doce. Eventualmente, e com menos frequência, pode ocorrer a fabricação de produtos no setor com sabor salgado. No local estão dispostos 3 operadores, os quais trabalham em dois níveis diferentes de piso. Em um nível inferior, denominado aqui como 1ํ nível, ficam os tanques de preparo e espera do xarope, forno, resfriador, balanças e saída do silo de espera do produto (ver Figura 2). Já, no $2^{\circ}$ nível, que fica 3 metros acima do $1^{\circ}$ nível, encontra-se o tambor de cobertura, um painel de controle das máquinas, peneira e entrada do silo de espera (ver Figura 3). Logo na saída do tambor de cobertura do $2^{\circ}$ nível encontra-se instalado um forno industrial do tipo túnel, com aproximadamente 15 metros de comprimento, onde as coberturas são secas e cristalizadas. Na extremidade deste forno encontram-se instalados um resfriador, uma peneira vibratória e o sistema de paletização, apresentado na Figura 3. 
Figura 2 - Vista lateral do $1^{\circ}$ nível no setor prioritário

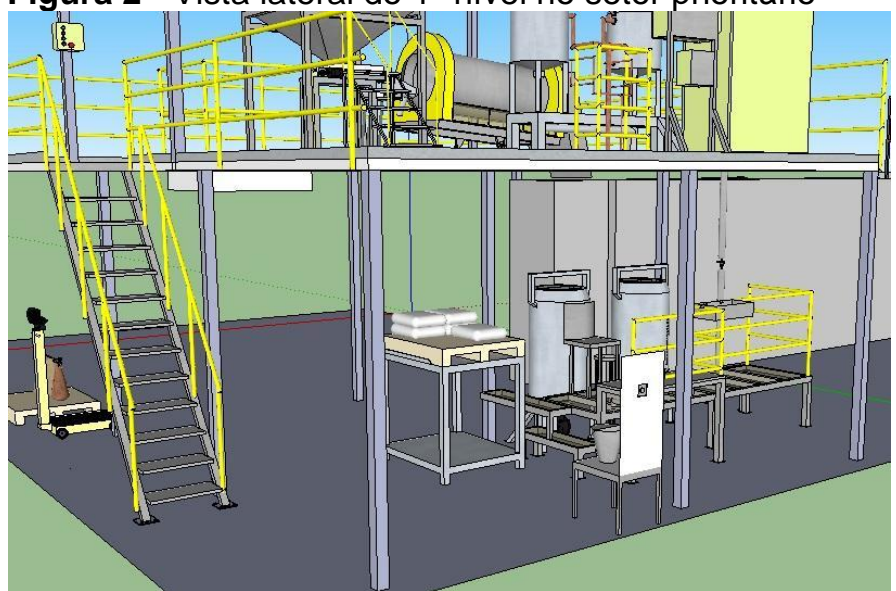

Figura 3 - Vista superior do $2^{\circ}$ nível presente no setor prioritário

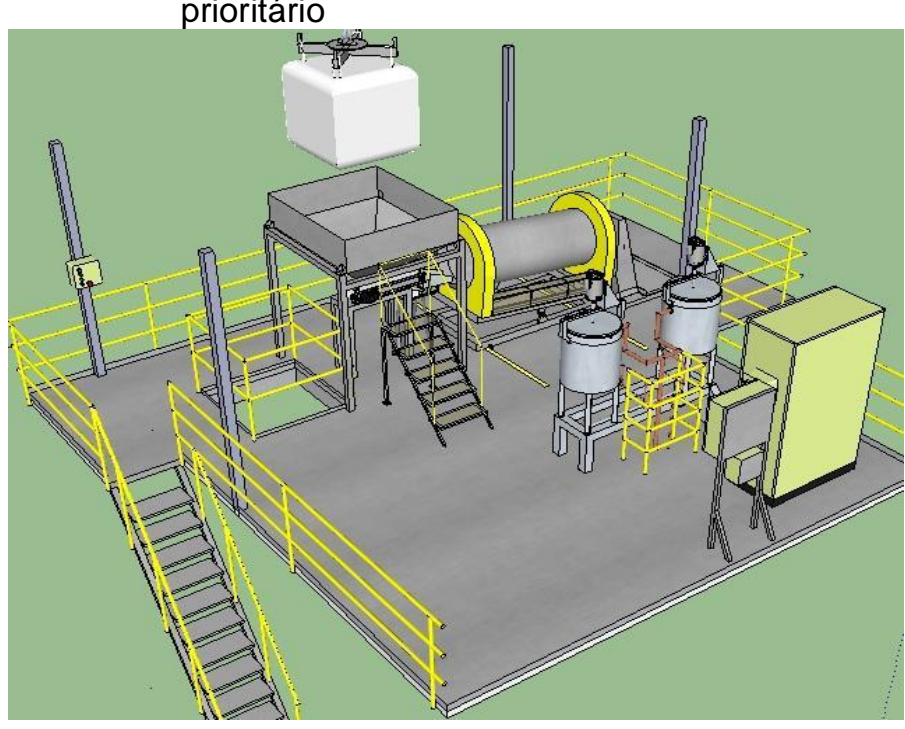

Figura 4 - Peneira vibratória e o sistema de paletização

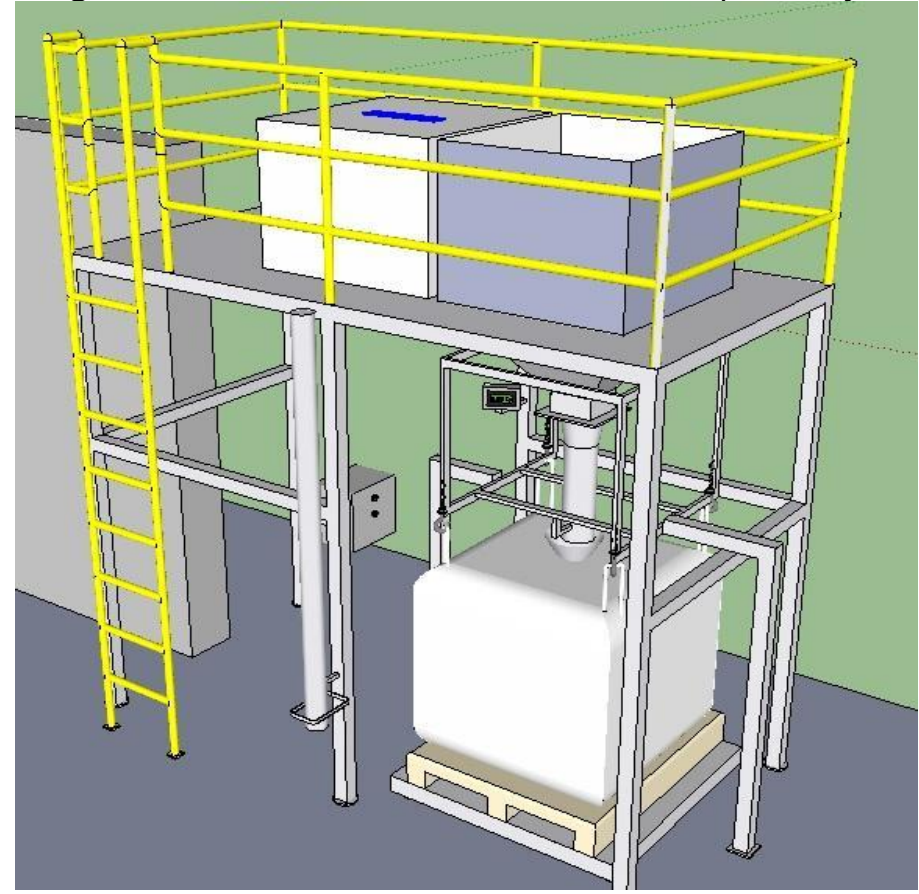

Revista Produção Online. Florianópolis, SC, v. 19, n. 4, p. 1369-1397, 2019 
Os locais presentes neste setor demandavam análise das posturas de trabalho, análise dos esforços (levantamento de carga e repetitividade) e as respectivas medidas preventivas necessárias relacionadas aos colaboradores que atuavam nos postos de trabalho do setor citado. A Figura 5 ilustra o fluxo do processo no Setor de Cobertura.

Figura 5 - Fluxograma do processo do Setor Cobertura

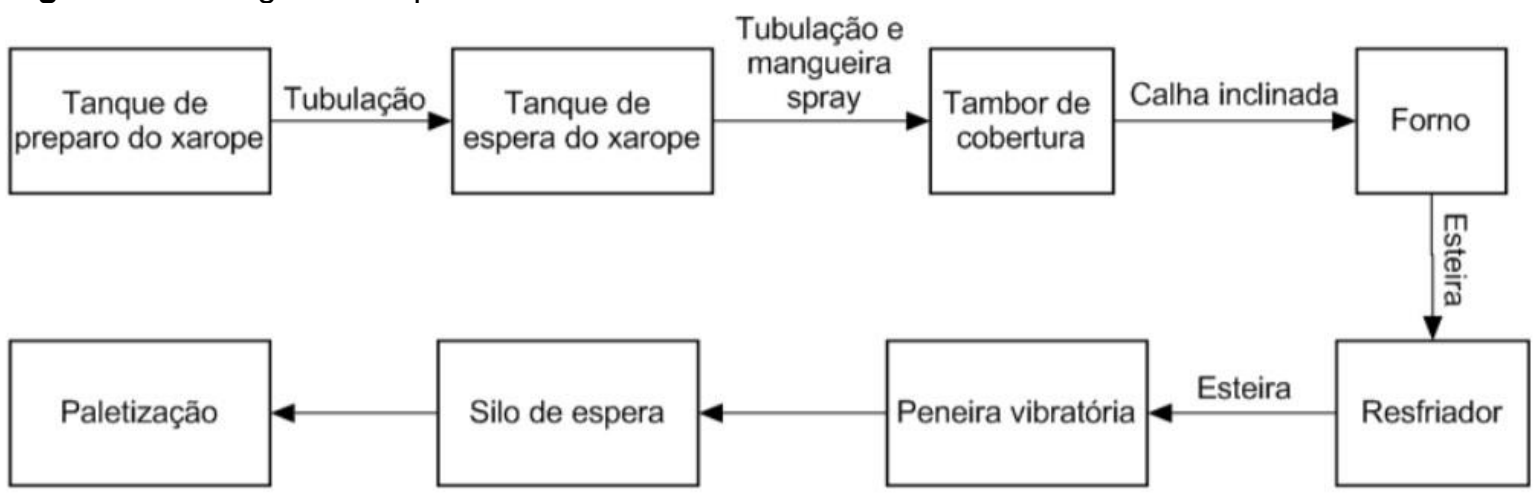

\subsection{Compreensão das atividades}

Conforme estabelecido na identificação da demanda, três postos se mostraram relevantes para serem estudados em profundidade na presente pesquisa, sendo eles aquele chamado Posto 1 (Operador 1), o Posto 2 (Operador 2) e o Posto 3 (Operador 3 ).

\subsubsection{Análise da Atividade no Posto 1}

Inicialmente o Operador 1 precisa verificar a ordem de produção, efetuar a limpeza completa do setor, retirar a matéria-prima do estoque, ligar os equipamentos, verificar a proporção de dosagem do produto, inserir o produto no tambor de cobertura e monitorar o processo (monitorar o painel de controle das máquinas, temperatura do forno e resfriador, velocidade das esteiras). Na Figura 6 apresenta-se o Operador 1 em seu posto de trabalho, junto ao tambor de cobertura. 


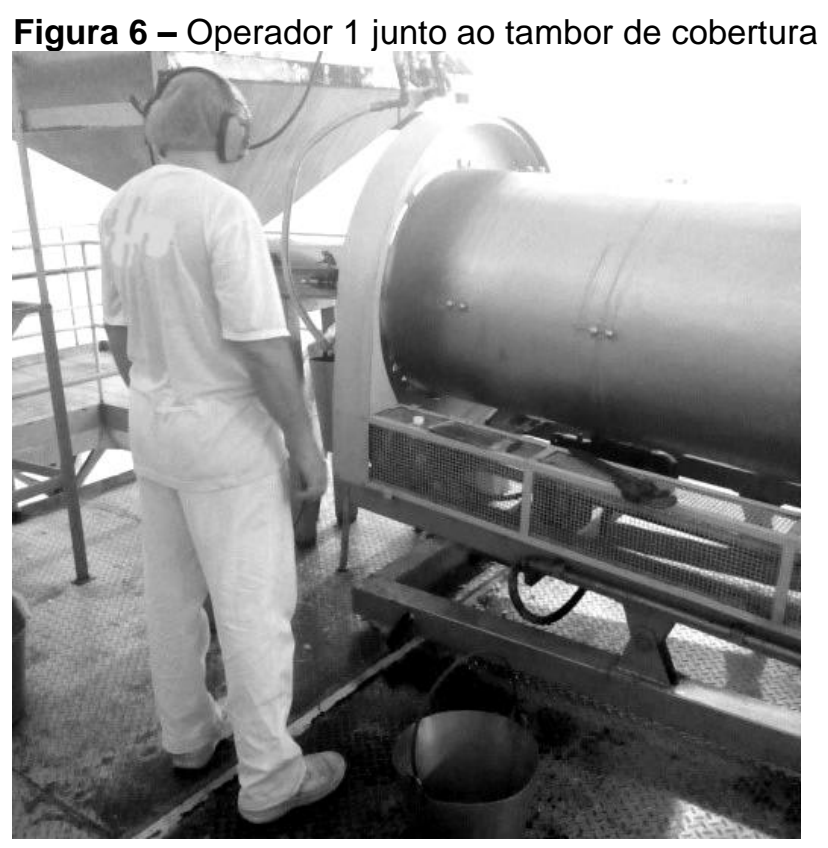

Figura 7 - Vista superior do Posto 1 da área de cobertura

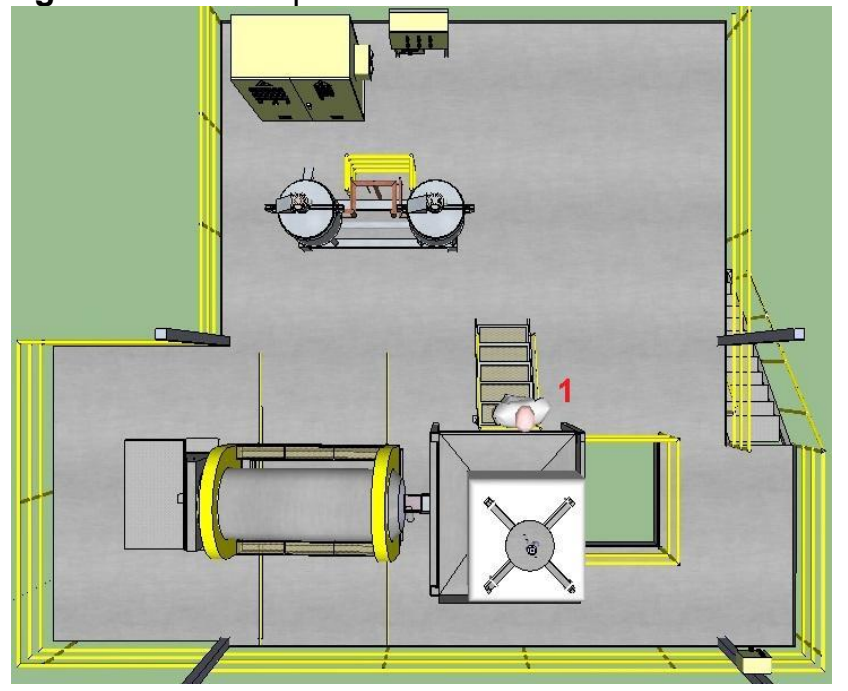

Para definir a proporção para a dosagem do produto, o operador com auxílio de um cronômetro, verifica a quantidade de xarope e da mistura que são disponibilizadas por minuto, uma vez estando de acordo com o parâmetro elaborado pelo setor de desenvolvimento, pode-se iniciar a produção, caso não esteja, deverá realizar a alteração nos parâmetros das máquinas visando obter uma nova medição.

\subsubsection{Análise da atividade no Posto 2}

O Operador 2 que trabalha nesse posto é responsável por buscar a matéria-prima no estoque, preparar o xarope, realizar o teste Brix do xarope e a limpeza dos tanques. 
O teor Brix, testado pelo operador, nada mais é que uma referência à porcentagem de sólidos solúveis (açúcares e sais), presentes no xarope sob preparo. Essa análise considera que as soluções açucaradas apresentam a mesma densidade na mesma concentração, mesmo que o açúcar seja diferente. O teor de Brix pode ser determinado através da densimetria ou refratometria (CTC, 2011). Para a preparação do xarope o funcionário precisa inserir as matérias primas dentro do tanque de preparo.

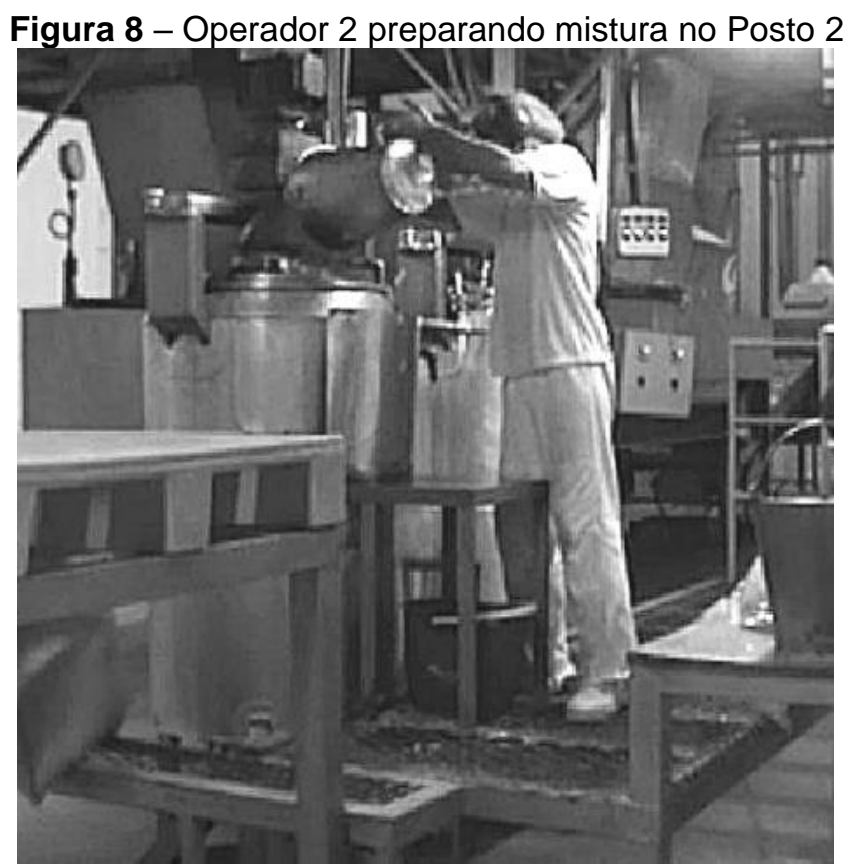

A Figura 9 apresenta a vista superior do Posto 2.

Figura 9 - Vista superior do Posto de Trabalho 2 da área de cobertura

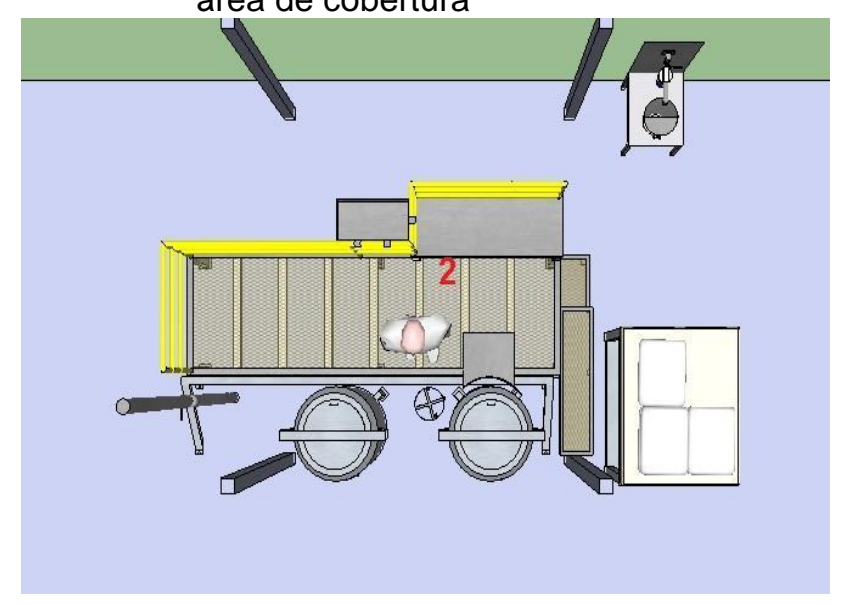

O Operador 2 também deve controlar e monitorar a pressão da máquina. Se o processo for feito com pressão máxima, o xarope pode ficar com cristais de açúcar e 
acabar causando o entupimento da mangueira que o leva até o tambor de cobertura. Após o preparo do xarope, o Operador 2 retira uma amostra e leva até o laboratório de análise da qualidade, no qual ele próprio efetua o teste Brix. O xarope só poderá passar do tanque de preparo para o tanque de espera se a amostra for aprovada neste teste.

Uma vez estando correta a especificação do xarope, este é direcionado para o tanque de espera através de válvulas acionadas pelo operador que, por fim, envia o xarope do tanque de espera para o tambor de cobertura. O caminho inverso também é permitido, ou seja, o produto que ainda está na mangueira pode retornar ao tanque de espera e de preparo, embora, o xarope que já foi despejado no tambor não retorna por já ter entrado em contato com o produto.

\subsubsection{Análise da Atividade no Posto 3}

O Operador 3 fica responsável por posicionar o bag que será preenchido com o produto no final da linha, conforme apresentado na Figura 10. Na balança há fixado um palete plástico sendo que, o Operador 3 coloca um palete na frente da balança para depois de preenchido o bag, mover o bag entre paletes. No palete plástico é colocado bag vazio, se prende suas alças com o auxílio de correntes e se insere o bocal do bag na saída do funil.

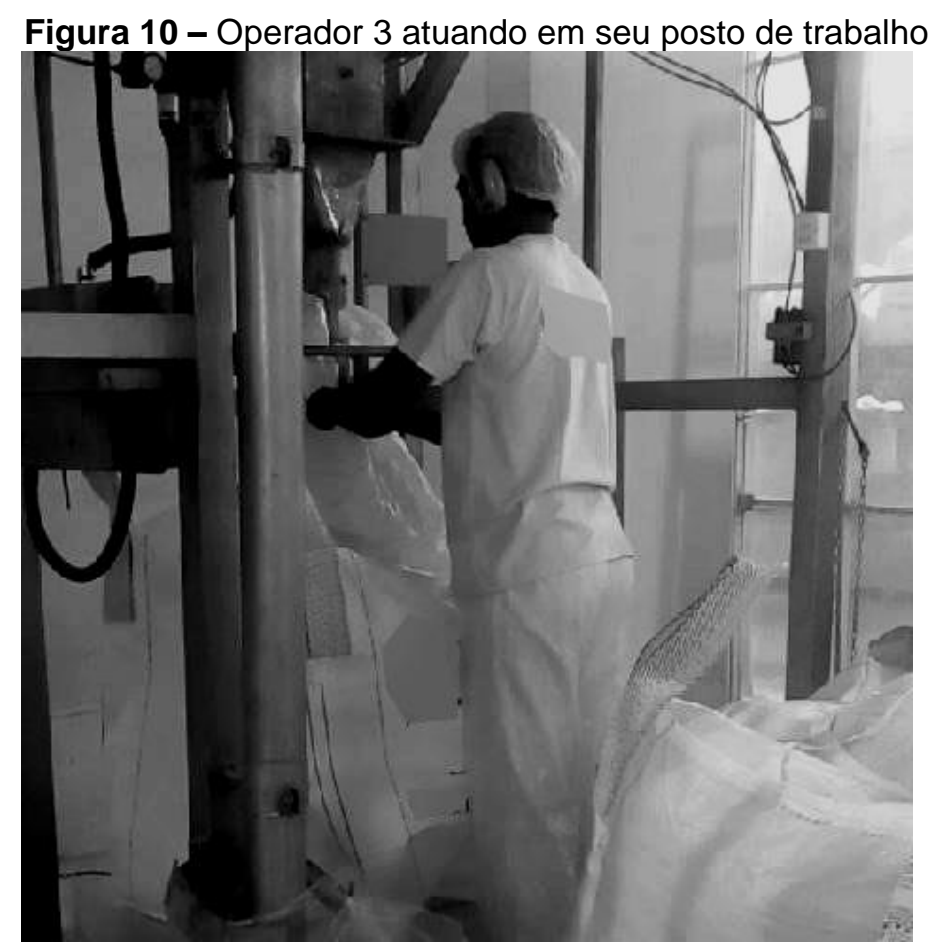


Após o bag ser preenchido com a quantidade estipulada, o operador interrompe a saída do produto acionando uma alavanca, retira o bag do palete e repõe outro bag vazio no local, conforme pode se observar na Figura 11. Após a troca do bag, o operador deve preencher uma planilha de troca, onde irá inserir as informações referentes aquele bag. Uma vez preenchido o bag, o Operador 3 o retira e posiciona no setor de destino. O operador deve colocar em uma das suas alças uma etiqueta contendo as informações do bag (número do lote, data e turno de fabricação, operador responsável) e aguardar a folha de lançamento.

Figura 11 - Operador 3 manuseando o bag no momento da troca de palete

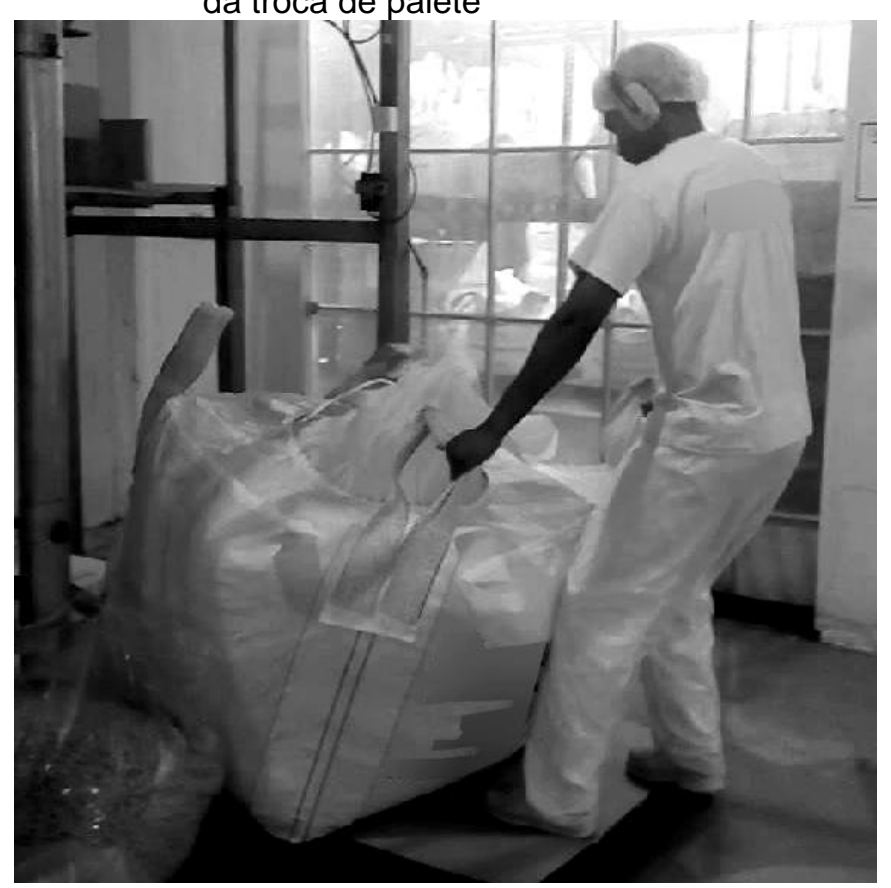

Após ser colada a folha de lançamento no bag, o operador deve levar o bag até a área de espera onde posteriormente será encaminhada ao estoque. A cada bag preenchido, processo que leva em torno de 40 minutos, o operador deve retirar uma amostra do produto final. Ao fim do turno as amostras são encaminhadas para o laboratório da qualidade onde será realizado o teste de conformidade do lote. O Operador 3 ainda deve realizar a troca dos sacos onde os resíduos de final do lote de produção são depositados. Estes resíduos são colocados no palete e transportados até a área de descarte da empresa. Ele ainda ajuda na limpeza do setor.

O Operador 3 deve verificar a densidade do produto final com uma frequência de 10 minutos, verificar a umidade do produto final com uma frequência de 30 minutos, 
retirar os resíduos da produção e preencher as planilhas de controle de produção. Para tanto, ele percorre uma distância aproximada de $44 \mathrm{~m}$ para fazer o teste de densidade.

Cada vez que o Operador 3 realizar o teste de densidade e umidade do produto, deverá preencher a planilha de controle do teste. Caso o produto apresente densidade ou umidade não conforme, o operador 3 deve informar ao operador 1 para fazer ajustes nas máquinas da linha através do painel de comando e o produto não conforme deverá passar por reprocesso. Este operador, além de fazer o teste de densidade e umidade, deve preencher as planilhas de controle da mistura e resumo da produção.

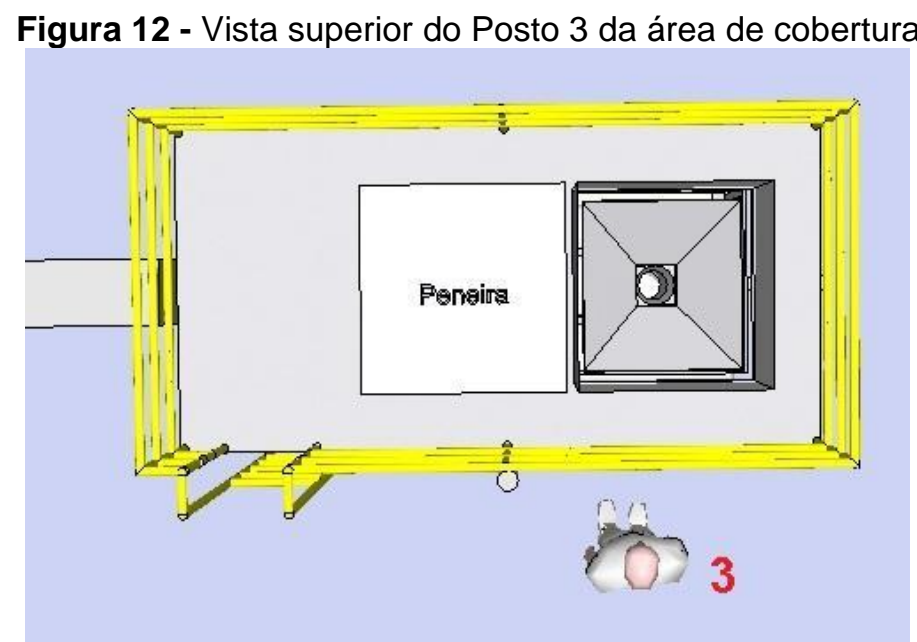

\subsection{Diagnósticos}

Tendo em mãos as informações provenientes da Análise da Demanda e da Atividade, foi possível traçar um diagnóstico preliminar dos postos sob estudo. Como os três postos analisados se encontram dentro de um grande e único ambiente, alguns riscos acabam afetando simultaneamente os operadores nos três postos analisados. $O$ principal risco neste sentido refere-se à exposição dos trabalhadores a temperaturas extremas. Verificou-se, neste caso, que a temperatura elevada durante a execução das atividades se mostrou um agravante importante do ponto de vista ergonômico. O local não possui ventilação com vistas a garantia de conforto térmico, o que pode pode causar uma sobrecarga no sistema cardiovascular, devido à demanda de grande circulação sanguínea para manter o equilíbrio da temperatura corporal dos operadores. Dentre os efeitos possíveis encontram-se adversidades como tontura, mal-estar e sensação de fadiga. 


\subsubsection{Riscos e Técnicas de análise aplicadas no Posto 1}

Foram identificados alguns riscos ergonômicos aparentes para esse posto de trabalho, dentre os quais, se destaca a sobrecarga dos membros inferiores devido à frequente movimentação entre os diferentes níveis do ambiente de trabalho. Constantemente o operador precisa subir e descer as escadas o que pode, por exemplo, resultar em dores nas pernas. Não obstante, as atividades no local ainda exigem levantamento, manuseio e transporte de carga. Complementar a isso, há ainda perigo de queda na escada, devido ao fato de precisar transportar cargas ao se deslocar.

Constatou-se ainda que a execução da atividade de pesagem da dosagem do produto exige que o operador faça frequentes deslocamentos através da escada para fazer a pesagem da dosagem do produto. Caso a proporção não esteja correta, o mesmo deverá corrigir os parâmetros do processo e realizar novas medições até que se alcance o valor estipulado pela formulação elaborado pelo setor de desenvolvimento de produtos. Tais deslocamentos possuem potencial para causar sensação de fadiga e dor nos membros inferiores, situação que pode ser agravada pela carga do balde contendo o acúmulo do peso do xarope (aproximadamente $5 \mathrm{~kg}$ ) quanto o material sólido (aproximadamente $7 \mathrm{~kg}$ ). Visando mensurar o nível de exposição aos riscos evidenciados e com especial atenção ao caso dos membros superiores, foi aplicado nesta atividade o índice Strain Index, chegando ao resultado apresentado na Tabela 1.

Tabela 1 - Resultado após aplicação do Strain Index para tarefa de pesar a dosagem do produto

\begin{tabular}{ccccccc}
\hline $\begin{array}{c}\text { Fator de } \\
\text { Intensidade } \\
\text { do Esforço } \\
\text { (FIE) }\end{array}$ & $\begin{array}{c}\text { Fator de } \\
\text { Duração do } \\
\text { Esforço } \\
\text { (FDE) }\end{array}$ & $\begin{array}{c}\text { Fator de } \\
\text { Frequência } \\
\text { do Esforço } \\
\text { (FFE) }\end{array}$ & $\begin{array}{c}\text { Fator de } \\
\text { Postura da } \\
\text { Mão/Punho } \\
\text { (FPMP) }\end{array}$ & $\begin{array}{c}\text { Fator de } \\
\text { Ritmo do } \\
\text { Trabalho } \\
\text { (FRT) }\end{array}$ & $\begin{array}{c}\text { Fator de } \\
\text { Duração } \\
\text { do trabalho } \\
\text { (FDT) }\end{array}$ & $\begin{array}{c}\text { Índice } \\
\text { de }\end{array}$ \\
\hline 3 & 3 & 0,5 & 1 & 1 & 1 & 4,50 \\
\hline
\end{tabular}

O resultado encontrado indicou que esta atividade não estava totalmente adequada do ponto de vista ergonômico, apresentando risco intermediário.

A execução da atividade de retirada de resíduos para descarte, por sua vez, também exige que o operador faça frequentes deslocamentos através da escada para a retirada do saco de resíduos (podendo variar entre 20 e $30 \mathrm{~kg}$ ), e realizar a sua substituição por um vazio. Esta situação ainda é agravada tanto pela irregularidade no formato do saco de resíduos (maleável e volumoso), quanto pelo seu peso. Visando 
mensurar o nível de exposição a problemas potenciais para os membros superiores, foi aplicado também a esta atividade o método Strain Index, obtendo-se como resultado os dados presentes na Tabela 2.

Tabela 2 - Resultado após aplicação do Strain Index para tarefa de retirar saco de resíduo

\begin{tabular}{ccccccc}
\hline $\begin{array}{c}\text { Fator de } \\
\text { Intensidade } \\
\text { do Esforço } \\
\text { (FIE) }\end{array}$ & $\begin{array}{c}\text { Fator de } \\
\text { Duração do } \\
\text { Esforço } \\
\text { (FDE) }\end{array}$ & $\begin{array}{c}\text { Fator de } \\
\text { Frequência } \\
\text { do Esforço } \\
\text { (FFE) }\end{array}$ & $\begin{array}{c}\text { Fator de } \\
\text { Postura da } \\
\text { Mão/-Punho } \\
\text { (FPMP) }\end{array}$ & $\begin{array}{c}\text { Fator de } \\
\text { Ritmo do } \\
\text { Trabalho } \\
\text { (FRT) }\end{array}$ & $\begin{array}{c}\text { Fator de } \\
\text { Duração } \\
\text { do trabalho } \\
\text { (FDT) }\end{array}$ & $\begin{array}{c}\text { Índice } \\
\text { de } \\
\text { Risco }\end{array}$ \\
\hline 9 & 1,5 & 0,5 & 2 & 1 & 1 & 13,50 \\
\hline
\end{tabular}

O resultado encontrado pela aplicação do método indicou que esta atividade apresentava risco significativo para o operador.

\subsubsection{Riscos e Técnicas de análise aplicadas no Posto 2}

Neste posto também verificou-se a necessidade constante de deslocamentos do operador, embora em seu caso, não ocorra com frequência a necessidade de subir a escada que leva ao nível superior. Aqui também os deslocamentos possuem potencial para causar sensação de fadiga e dores, devido à sobrecarga dos membros inferiores sendo que, neste posto também há a necessidade de carregar o balde de inox (que pesa aproximadamente $5 \mathrm{~kg}$ ), onde é transportado água, o que resulta em um peso final $15 \mathrm{~kg}$ quando o balde está cheio.

O posto possui duas atividades bastante distintas, sendo uma delas aquela que envolve a inserção de açúcar no tanque de preparo e a segundo, que envolve a inserção de água nestes mesmos tanques.

Para o caso da atividade de inserir açúcar no tanque de preparo optou-se pela aplicação do Método Rula e da Equação de NIOSH. Na aplicação do método RULA utilizou-se de registros fotográficos e filmagens, bem como informações referentes às posturas durante a execução das atividades. Para tanto, foi retirada da filmagem referência uma sequência de quadros, de modo que se pudesse ter um panorama da postura adotada em cada fase da atividade, analisando separadamente cada lado do corpo.

Por fim, tendo conhecimento do ciclo de trabalho e das tarefas envolvidas, a atividade foi dividida em 4 fases, sendo elas a Fase 1 (Abrir embalagem), Fase 2 (Inserir 
açúcar no tanque de preparo com a caneca), a Fase 3 (Virar embalagem no tanque de preparo) e, por fim, a Fase 4 (Pegar a embalagem no palete). Com a aplicação do RULA foi possível obter os resultados apresentados na Figura 13, no qual apresenta-se os score obtidos para ambos os lados do operador.

Pode-se observar pela Figura 13 que as fases referentes ao lado esquerdo analisadas concentram-se predominantemente no score 3, enquadrando-se na Classe II do método RULA, a qual sugere uma investigação, pois são necessárias ações de melhoria. Já, as atividades da Fase 3 (virar embalagem no tanque de preparo) apresentam escores 6 e 7 , indicando que para esta atividade deve-se investigar e tomar ações imediatamente.

Figura 13 - Gráfico de scores obtidos em relação aos lados direito e esquerdo do corpo LADO ESQUERDO DO OPERADOR LADO DIREITO DO OPERADOR

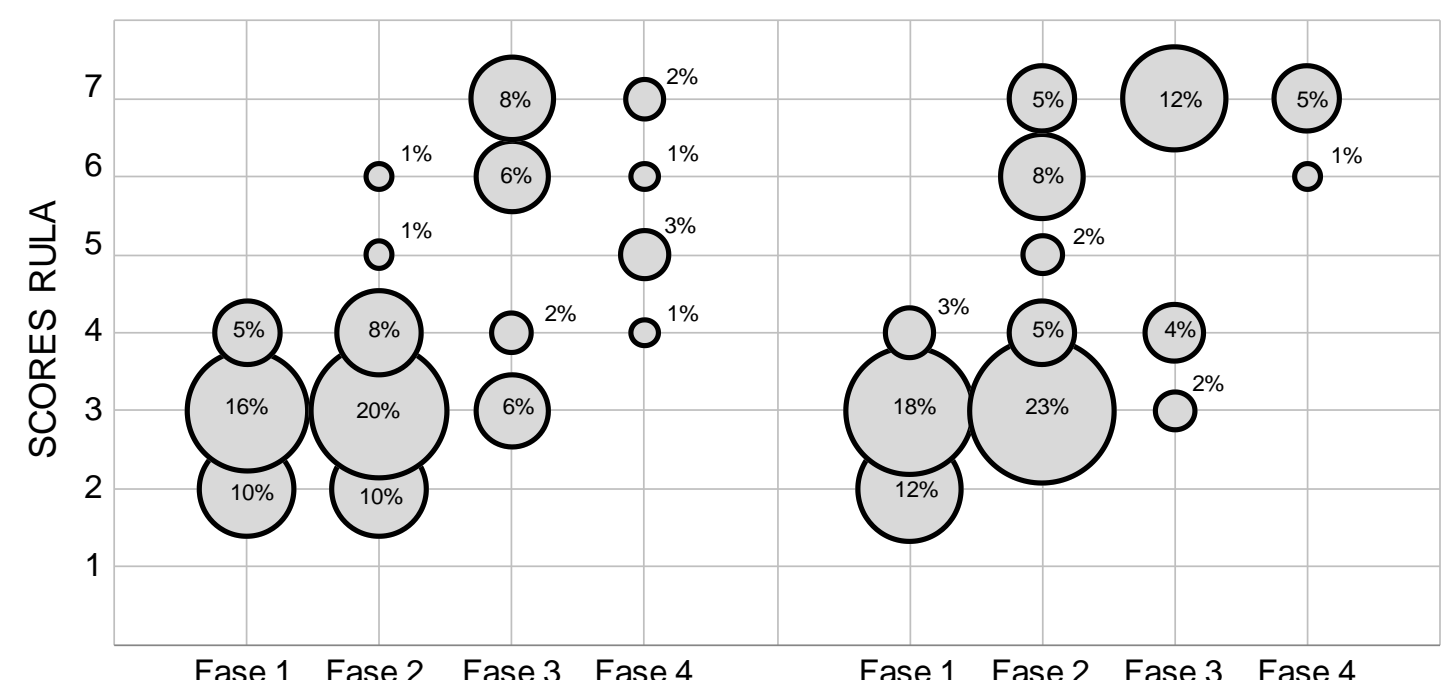

Segundo pode ser notado na Figura 13, as fases referentes ao lado esquerdo concentram-se predominantemente no score 3 , enquadrando-se na Classe II do método RULA, a qual sugere uma investigação, pois são necessárias ações de melhoria. Diferente do que acontecia com o lado esquerdo, aqui as atividades da Fase 2 e Fase 4, além da Fase 3, apresentam escores 6 e 7, indicando que para estas atividades devese investigar e tomar ações imediatamente.

Para esta atividade também foi aplicado método de $\mathrm{NIOSH}$, para este método foi obtido o resultado apresentado na Tabela 3. 
Tabela 3 - Resultados obtidos após aplicação do Método de NIOSH na atividade de inserir açúcar no tanque de preparo

\begin{tabular}{cccccccc}
\hline $\begin{array}{c}\text { Constante } \\
\text { de carga } \\
(\mathrm{LC})\end{array}$ & $\begin{array}{c}\text { Distância } \\
\text { Horizontal } \\
\text { (HM) }\end{array}$ & $\begin{array}{c}\text { Distância } \\
\text { Vertical } \\
\text { das mãos } \\
\text { (VM) }\end{array}$ & $\begin{array}{c}\text { Distância } \\
\text { vertical } \\
\text { ransporte } \\
\text { (DM) }\end{array}$ & $\begin{array}{c}\text { Ângulo } \\
\text { assimetria } \\
\text { (AM) }\end{array}$ & $\begin{array}{c}\text { Frequência } \\
\text { média } \\
\text { levantamento } \\
\text { (FM) }\end{array}$ & $\begin{array}{c}\text { Qualidade } \\
\text { da pega } \\
\text { (CM) }\end{array}$ & $\begin{array}{c}\text { Limite de } \\
\text { Peso }\end{array}$ \\
\hline 23 & 1 & 0,952 & 0,865 & 1 & 0,85 & 0,90 & $\begin{array}{c}\text { Recomendado } \\
\text { (LPR) }\end{array}$ \\
\hline
\end{tabular}

De acordo com o Limite de Peso Recomendado (LPR) obtido, o índice de levantamento (quociente entre o peso da carga levantada com o peso da carga recomendada) foi calculado por meio da Equação 1, o que resultou em um valor de Índice de Levantamento de 1,73.

$$
\begin{aligned}
\mathrm{IL} & =\mathrm{PC} / \mathrm{LPR} \\
\mathrm{IL} & =25 / 14,49 \\
\mathrm{IL} & =1,73
\end{aligned}
$$

Assim, IL é $1<\mathrm{IL}<3$, definindo que alguns trabalhadores podem adoecer ou sofrer lesões se realizam essas tarefas. Essas devem ser redesenhadas ou atribuídas apenas a trabalhadores selecionados que serão submetidos a controle.

Para aplicação do método RULA, na atividade de inserir água no tanque de preparo, coletou-se através de registros fotográficos e filmagens, informações referentes às posturas durante a execução das atividades. Foi extraído de uma filmagem referência, uma sequência de quadros, de modo que se pudesse ter um panorama da postura adotada em cada fase da atividade, analisando separadamente cada lado do corpo. Tomando por base a rotina de trabalho, a atividade foi dividida em 3 fases, sendo elas a Fase 1 (Pegar balde), a Fase 2 (Erguer balde), e a Fase 3 (Descer balde). Após aplicação da avaliação, obteve os resultados apresentados na Figura 14.

Conforme pode-se observar pela Figura 14, as fases referentes ao lado esquerdo analisadas concentram-se predominantemente no score 7, enquadrando-se na Classe IV do método RULA, a qual sugere uma investigação, pois são necessárias ações de melhoria imediatamente. 
Figura 14 - Gráfico de scores obtidos em relação aos lados esquerdo e direito do corpo LADO ESQUERDO DO OPERADOR

LADO DIREITO DO OPERADOR

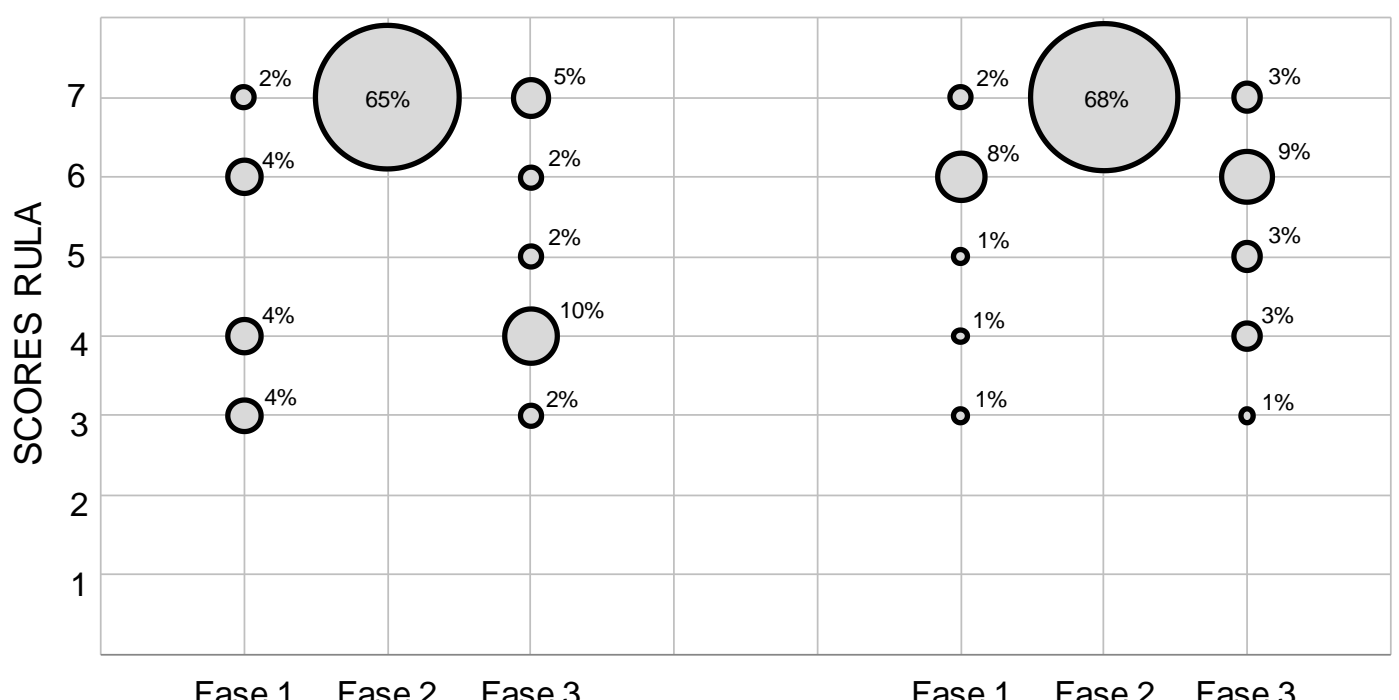

No caso do lado direito também verificou-se predominantemente no score 7 (ver Figura 14), enquadrando-se na Classe IV do método RULA, a qual sugere uma investigação, pois são necessárias ações de melhoria imediatamente.

Em complemento ao RULA, também aplicou-se para a atividade de inserção de água no tanque o método de $\mathrm{NIOSH}$, onde foi obtido o resultado apresentado na Tabela 4. Portanto, conforme pode-se verificar pela referida tabela, o operador pode exercer suas atividades envolvendo a manutenção de cargas da ordem de $15,32 \mathrm{~kg}$, o que se encontra-se ligeiramente acima do peso que ele carrega atualmente.

Tabela 4 - Método de NIOSH na atividade de inserir água no tanque de preparo

\begin{tabular}{cccccccc}
$\begin{array}{c}\text { Constante } \\
\text { de carga } \\
\text { (LC) }\end{array}$ & $\begin{array}{c}\text { Distância } \\
\text { Horizontal } \\
\text { (HM) }\end{array}$ & $\begin{array}{c}\text { Distância } \\
\text { Vertical } \\
\text { das mãos } \\
\text { (VM) }\end{array}$ & $\begin{array}{c}\text { Distância } \\
\text { vertical } \\
\text { transport } \\
\text { e (DM) }\end{array}$ & $\begin{array}{c}\text { Ângulo } \\
\text { assimetria } \\
\text { (AM) }\end{array}$ & $\begin{array}{c}\text { Frequência } \\
\text { média } \\
\text { levantamento } \\
\text { (FM) }\end{array}$ & $\begin{array}{c}\text { Qualidade } \\
\text { da pega } \\
\text { (CM) }\end{array}$ & $\begin{array}{c}\text { Limite de Peso } \\
\text { Recomendado } \\
\text { (LPR) }\end{array}$ \\
23 & 1 & 0,985 & 0,8842 & 1 & 0,85 & 0,90 & 15,32 \\
\hline
\end{tabular}

De acordo com o CLR obtido, o índice de levantamento (quociente entre o peso da carga levantada com o peso da carga recomendada) foi calculado um Índice de Levantamento de 0,9 . Este IL é menor de 1,0, no qual se convenciona que a maioria dos trabalhadores que realizam este tipo de tarefa não deveria ter problemas. Contudo, esta atividade não deve ser analisada de forma isolada. Sendo assim, e visando contemplar a tarefa de maneira mais global, foi aplicado o índice de Strain Index considerando desde o 
momento da retirada do balde da torneira até a inserção do seu conteúdo no tanque de preparo. Os resultados obtidos de sua aplicação constam na Tabela 5.

Tabela 5 - Índice de Strain Index considerando desde o momento da retirada do balde da torneira até a inserção do seu conteúdo no tanque de preparo

\begin{tabular}{ccccccc}
\hline $\begin{array}{c}\text { Fator de } \\
\text { Intensidade } \\
\text { do Esforço } \\
\text { (FIE) }\end{array}$ & $\begin{array}{c}\text { Fator de } \\
\text { Duração do } \\
\text { Esforço } \\
\text { (FDE) }\end{array}$ & $\begin{array}{c}\text { Fator de } \\
\text { Frequência } \\
\text { do Esforço } \\
\text { (FFE) }\end{array}$ & $\begin{array}{c}\text { Fator de } \\
\text { Postura da } \\
\text { Mão/-Punho } \\
\text { (FPMP) }\end{array}$ & $\begin{array}{c}\text { Fator de } \\
\text { Ritmo do } \\
\text { Trabalho } \\
\text { (FRT) }\end{array}$ & $\begin{array}{c}\text { Fator de } \\
\text { Duração } \\
\text { do trabalho } \\
\text { (FDT) }\end{array}$ & $\begin{array}{c}\text { Índice } \\
\text { de } \\
\text { Risco }\end{array}$ \\
\hline 13 & 2 & 0,5 & 2 & 1 & 1 & 26 \\
\hline
\end{tabular}

Conforme pode-se observar, o resultado encontrado (ISI=26,0), indica que esta atividade apresenta risco, possuindo problemas potenciais que devem ser apurados.

\subsubsection{Riscos e Técnicas de análise aplicadas no Posto 3}

Neste posto o risco que teve maior ênfase foi o transporte de carga pelo fato do operador ter que posicionar o bag vazio e posteriormente o bag cheio nos locais apropriados. Além de que, por essa ser uma atividade de posicionamento, problemas posturais relacionados a sobrecarga da lombar e sobrecarga dos membros superiores podem ocorrer.

O posto possui como atividade principal a troca do bag de palete, o operador posiciona o bag no final da linha vazio, sobre a palete, e coloca suas alças nos locais indicados. Após seu preenchimento, ele o transfere para outro palete e o transporta até o local apropriado dentro do setor. O operador também é responsável por retirar uma amostra do material cada vez que um novo bag é preenchido, ao final do turno essas amostras são encaminhadas para análises laboratoriais.

Como exposto anteriormente, por essa atividade compreender o transporte de cargas, sua sobrecarga concentra-se nos membros superiores, logo a aplicação do método RULA se mostrou mais apropriada. Para a aplicação, utilizou-se basicamente o mesmo procedimento descrito nos postos anteriores, coletou-se através de registros fotográficos e filmagens, informações referentes às posturas durante a execução das atividades.

Após retirou-se da filmagem referência uma sequência de quadros, para que fosse possível ter um panorama da postura adotada em cada fase da atividade, 
analisando separadamente cada lado do corpo. Por fim, tendo conhecimento do ciclo de trabalho e das tarefas envolvidas, a atividade foi dividida em 5 fases:

Tabela 6 - Fases identificadas no posto de trabalho nำ3

\begin{tabular}{ll} 
Fase 1 & Travar/destravar silo \\
Fase 2 & Soltar as alças e bocal do bag \\
Fase 3 & Mover o bag até o palete \\
Fase 4 & Inserir um novo bag \\
Fase 5 & Retirar etiqueta da alça do bag \\
\hline
\end{tabular}

Obtendo assim, os seguintes resultados mostrados na Figura 15:

Figura 15 - Gráfico de scores obtidos em relação aos lados esquerdo e direito

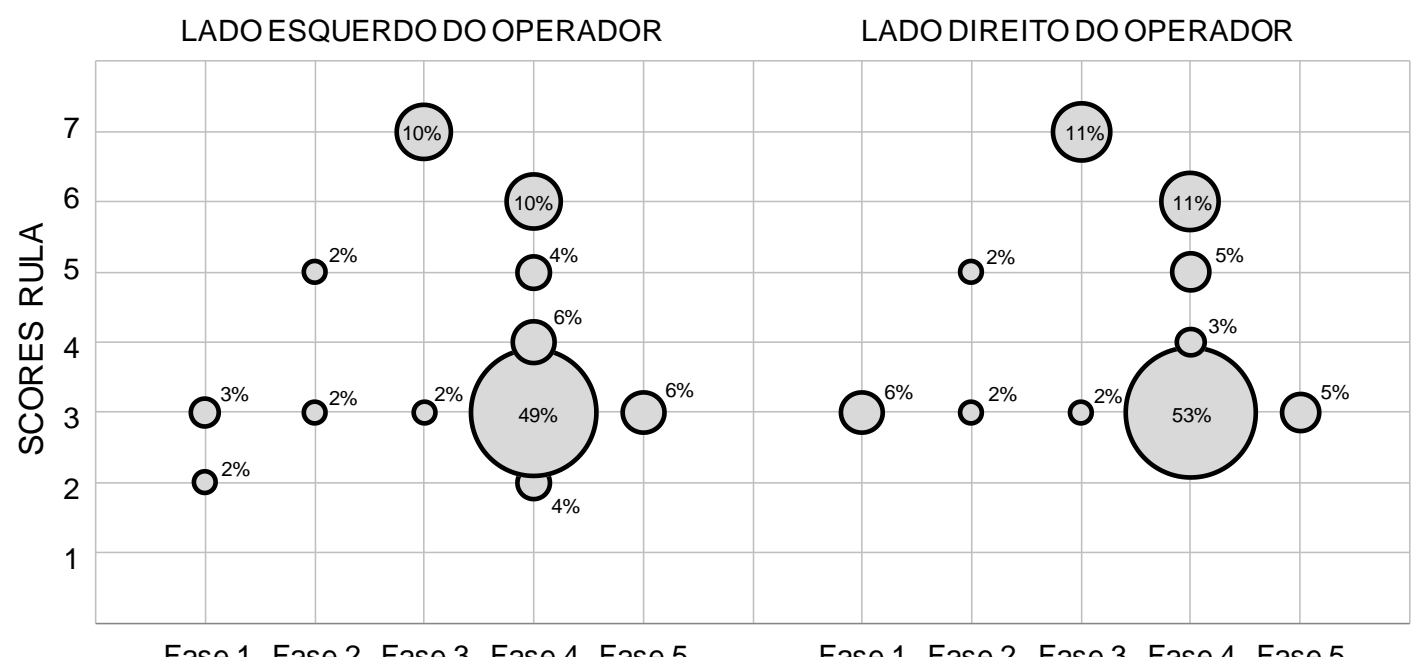

Conforme o gráfico acima, as fases referentes ao lado direito analisadas concentram-se predominantemente no score II, enquadrando-se na Classe II do método RULA, a qual sugere uma investigação, pois é possível que sejam necessárias ações de melhoria. Já as fases referentes ao lado esquerdo analisadas concentram-se predominantemente no score 3, enquadrando-se na Classe II do método RULA, a qual sugere uma investigação, pois é possível que sejam necessárias ações de melhoria.

A fase 3 - Mover o bag até o palete, apresentou escore 7 para ambos os membros superiores. Isto indica que esta tarefa exige uma investigação para correção imediata. Visando avaliar a tarefa da fase 3 foi aplicado a ferramenta Moore e Garg. 
Tabela 7 - Índice de Moore e Garg para tarefa de trocar o bag de palete

\begin{tabular}{|c|c|c|c|c|c|c|}
\hline $\begin{array}{c}\text { Fator de } \\
\text { Intensidade } \\
\text { do Esforço } \\
\text { (FIE) }\end{array}$ & $\begin{array}{l}\text { Fator de } \\
\text { Duração do } \\
\text { Esforço } \\
\text { (FDE) }\end{array}$ & $\begin{array}{l}\text { Fator de } \\
\text { Frequência } \\
\text { do Esforço } \\
\text { (FFE) }\end{array}$ & $\begin{array}{c}\text { Fator de } \\
\text { Postura da } \\
\text { Mão/-Punho } \\
\text { (FPMP) }\end{array}$ & $\begin{array}{c}\text { Fator de } \\
\text { Ritmo do } \\
\text { Trabalho } \\
\text { (FRT) }\end{array}$ & $\begin{array}{c}\text { Fator de } \\
\text { Duração } \\
\text { do trabalho } \\
\text { (FDT) }\end{array}$ & $\begin{array}{l}\text { Índice } \\
\text { de } \\
\text { Risco }\end{array}$ \\
\hline 13 & 1 & 0,5 & 1,5 & 1 & 1 & 9,75 \\
\hline
\end{tabular}

O resultado encontrado indica que esta atividade apresenta risco elevado para 0 colaborador.

\subsection{Recomendações ergonômicas}

Observa-se até este ponto da AET que a aplicação das técnicas de análise foi possível ainda que a tarefa, ou trabalho prescrito, não estivesse formalmente estabelecida. A identificação dos riscos foi, ainda que não conclusiva, praticável, permitindo avançar em direção à recomendações ergonômicas. Neste caminho, alguns pontos com possibilidade de melhorias emergiram no estudo, concordando com o que traz lida e Guimarães (2016) sobre como devem ser procedidas as AET típicas. Cabe apontar que algumas melhorias foram efetivamente implantadas no local abrangido pelo estudo.

No posto de trabalho $n^{0} 1$ (Operador 1), o maior desafio consistia em eliminar o frequente deslocamento através da escada entre os dois níveis. Uma proposta de melhoria consistiu na instalação de uma balança com altura adequada no segundo nível, para eliminar a necessidade de descer ao primeiro nível para realizar a pesagem durante a dosagem, conforme Figura 16.

Figura 16 - Imagem do posto 1 depois da modificação

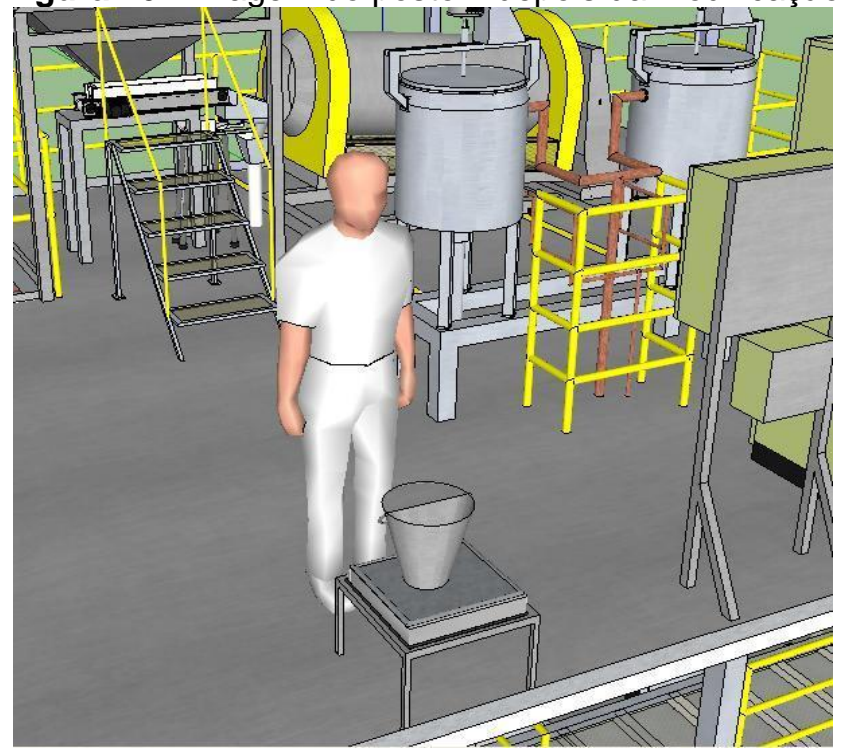


Outra melhoria consistiu em inserir um dispositivo para permitir que o resíduo presente na peneira disposta antes do tambor de cobertura, escorra diretamente até o nível inferior. Com isso foi possível eliminar a necessidade de transportar o saco de resíduos pela escada (ver Figua 17). Esta medida eliminou alguns riscos, dentre os quais, quedas na escada ao transportar o saco de resíduos.

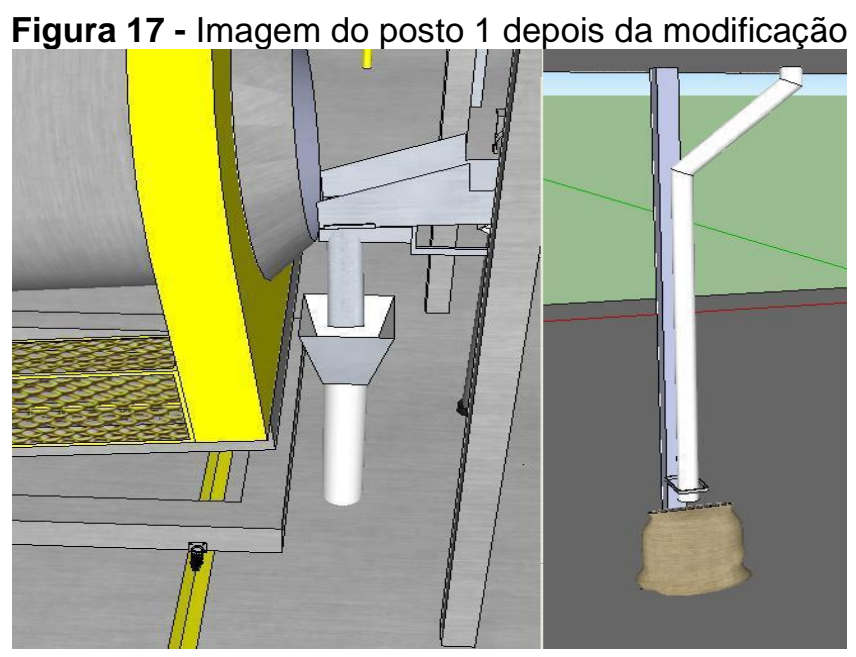

No que se refere ao caso do Operador 3, que fica predominante no nível inferior, notou-se uma demanda frequente de deslocamento para realizar os testes de densidade e umidade do produto. Este operador percorria antes da melhoria uma distância aproximada de $44 \mathrm{~m}$ para fazer o teste de densidade. Visando diminuir a necessidade de deslocamento para a realização dos testes de densidade do produto final, propõe-se a inserção de uma balança, conforme Figura 18, próxima a área de saída do produto acabado. Com a proposta de inserção da balança para realização do teste dentro da própria área da Cobertura, este deslocamento cai para aproximadamente 7 metros.

No posto de trabalho situado no nível inferior, onde se encontra o Operador 2 que prepara o xarope, o maior desafio era eliminar a necessidade de execução de atividades acima da linha do ombro. Sendo assim, uma proposta de melhoria foi a inserção de um dispositivo que transportasse a matéria-prima da altura do palete até o tanque de preparo, conforme apresentado na Figura 19. Além deste dispositivo, também foi sugerido a instalação de um equipamento que permitisse a inserção de água no tanque de preparo eliminando a necessidade de transportar manualmente os baldes e elevação dos braços acima da altura do ombro, conforme Figura 20. 
Figura 18 - Imagem do posto 3 depois da modificação

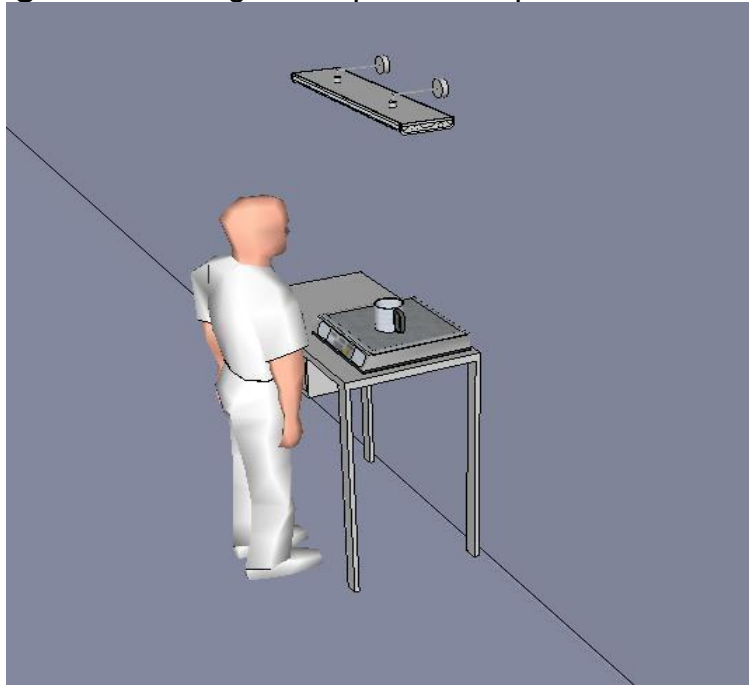

Figura 19 - Imagem do posto 2 com a inserção de um dispositivo para transporte de matéria prima

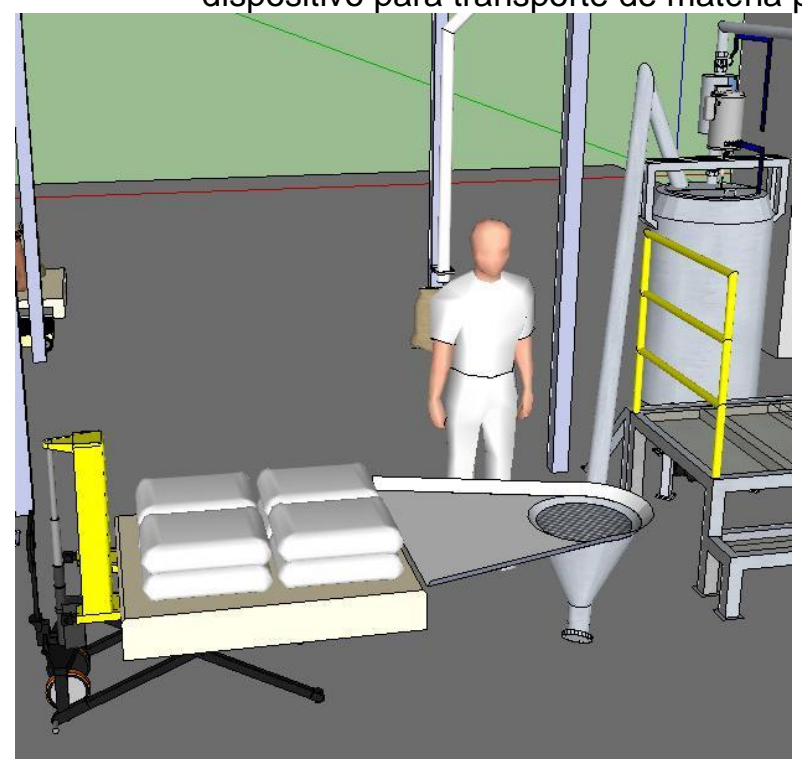

Figura 20 - Imagem do posto 2 com a inserção de

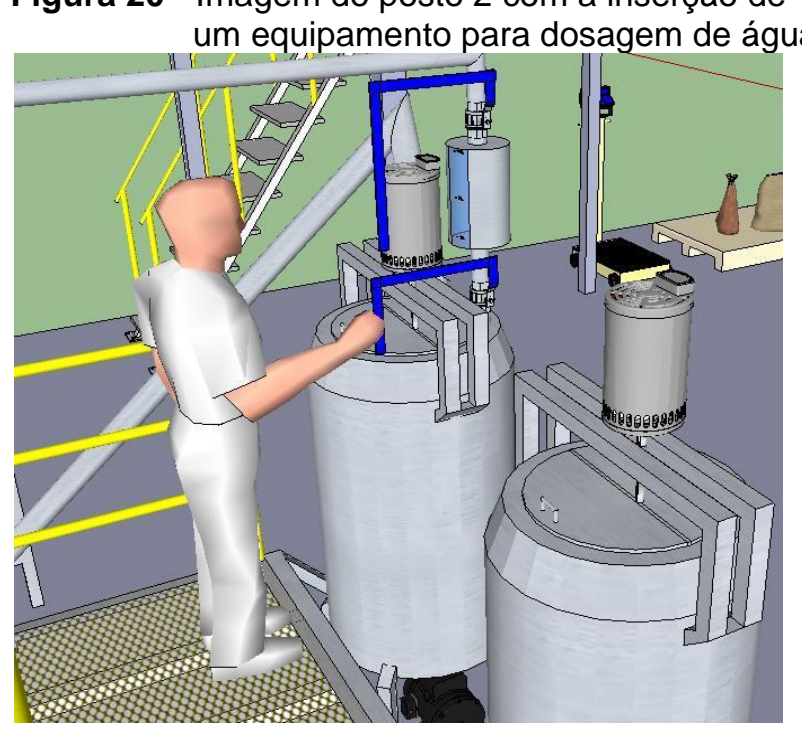


No posto de trabalho que fica após a secagem do produto, e onde fica alocado o Operador 3 que retira o produto final, o maior desafio era eliminar o deslocamento manual do bag entre paletes (ver Figura 21). Dessa forma, um encaminhamento foi utilizar uma rampa como meio de acesso ao palete sobre a balança para que o bag pudesse ser transportado através da paleteira.

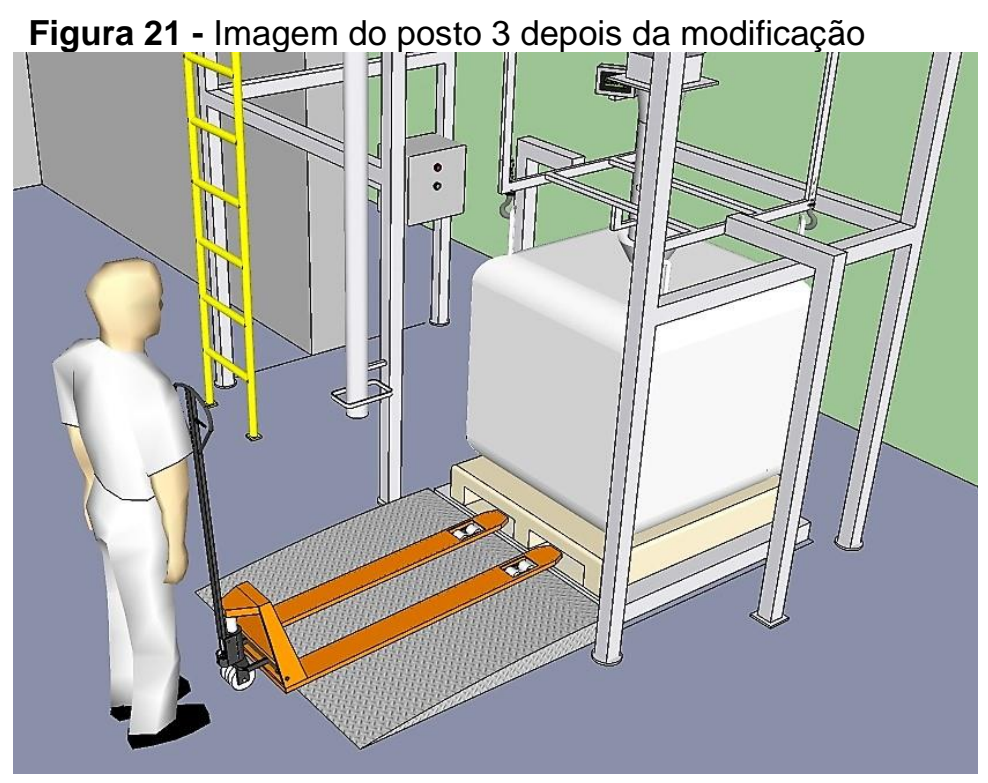

Um problema que abrangia todos os postos de trabalho, que consistia na ausência de conforto térmico, mostrou-se o elemento mais desafiador em termos de melhorias ergonômicas. Este problema provinha tanto da dissipação do calor do forno que estava presente no ambiente, quanto das características arquitetônicas do local, com paredes construídas em policloreto de vinil, popularmente conhecido pelo acrônimo PVC. Dado os custos envolvidos e as restrições técnicas existentes no local, um dos caminhos considerados neste caso foi uma ação em termos de Ergonomia Organizacional, onde a alocação dos funcionários e planejamento do processo envolveu uma menor permanência dos operadores nos locais onde os níveis de conforto térmico eram indesejáveis. Contudo, compreende-se esta medida como de caráter paliativo. Medidas mais robustas exigirão pesquisas futuras com foco exclusivamente na avaliação térmica do ambiente.

Verificou-se ainda que as recomendações ergonômicas presentes neste trabalho exigiram o cuidado para a padronização do processo e treinamento da equipe dos operadores e auxiliares de produção, pois uma dificuldade encontrada na análise das atividades foi exatamente a falta de padronização das etapas. No rodízio das funções ou 
na troca de turno verificou-se que cada colaborador executava suas tarefas de maneira que lhe era mais conveniente, ou seja, sem um modo operatório comum e compartilhado.

\subsection{Uma breve reflexão a partir do exposto}

Os resultados alcançados na AET em tela foram em sua maioria implantados a partir de soluções de baixo custo e em prazos que não excederam mais que três meses, não ocorrendo isso somente naqueles casos que demandavam grandes custos envolvendo reprojeto das instalações industriais. Percebe-se, portanto, que a AET pode trazer importantes contribuições em termos de melhoria nas operações. Essa constatação emerge pela vivência apresentada aqui, onde a implantação de soluções envolvendo a redução de deslocamentos, assim como a minimização de utilização de posturas indesejáveis, implicaram na diminuição ou supressão de elementos que não agregavam valor durante o processo.

Complementar a isso, fica visível no contexto da AET relatada que dentro de algumas circunstâncias é possível desenvolver a análise mesmo em um contexto onde a divisão entre o trabalho prescrito e o trabalho real não estão totalmente estabelecidos.

É necessário, contudo, que sejam estabelecidos claramente os contornos do modo operatório presente no local objeto do estudo, o que demanda tempo e cuidado por parte do analista.

Fica igualmente evidente a necessidade de uma atenção redobrada à observação atenta de todos os detalhes do processo, algo que por vezes, é negligenciado por alguns analistas. Ou seja, uma AET deve ser desenvolvida de forma não transversal e pontual, mas sim, longitudinalmente. Isso significa dizer que seu desenvolvimento deve contemplar observações, diálogos e registros de dados, os quais podem demandar em alguns casos várias semanas ou meses. Somente com tal cuidado é possível obter uma AET que contribua efetivamente para o negócio e não acabe por se tornar um documento sem uso e sem contribuições efetivas ao negócio.

Os caminhos indicados no presente trabalho, de um modo geral, constituíram-se em soluções simples e imediatas, além de demandarem baixos investimentos. Algumas soluções mais elaboradas implicaram na possibilidade de implantação de Comitês de Ergonomias (Coergos) e integração mais direta da CIPA no âmbito da Ergonomia, bem como o envolvimento dos funcionários em termos de Ergonomia de Participação, 
mudanças de layout, entre outras possibilidades. Contudo, tais soluções demandariam um envolvimento mais profundo na AET, extrapolando o escopo deste estudo, visto que não era esperado que se conseguisse tais soluções em um curto prazo.

\section{CONCLUSÕES}

Este artigo apresenta algumas constatações que merecem ser aqui sumarizadas. Primeiramente, verificou-se a manutenção de cargas como um desafio importante, sobretudo se somado aos frequentes deslocamentos dos operadores. As implicações deste desafio podem ser severas para a empresa, pois implicam em perdas ligadas à Ergonomia Física (desgaste físico dos funcionários) e também, em termos de Ergonomia Organizacional (perdas diretamente vinculadas à organização dos processos).

As perdas experimentadas pelos deslocamentos cotidianos e frequentes impactam diretamente em outras perdas ligadas à eficiência dos processos, ou seja, perdas financeiras. Estas, por sua vez, normalmente ficam ocultas em uma análise mais imediata e superficial do processo. Contudo, os tempos dedicados a deslocamentos que não agregam valor ao produto consistem em algumas das perdas mais importantes experimentadas por qualquer negócio. Portanto, seus efeitos quando as causas não são tratadas podem ser severos, inclusive, em termos de estratégia de negócios.

Um segundo desafio refere-se à necessidade de elevação dos braços acima da linha do ombro, identificado em várias operações no preparo do xarope e que eleva os escores nos métodos de análise aplicados. Este desafio foi minimizado com a diminuição dos esforços posturais, através da diminuição dos desníveis dentro das operações no posto de trabalho e com o uso de dispositivos e alteração do próprio posto.

O terceiro desafio refere-se à necessidade de deslocamento manual de grandes cargas, como é o caso do bag entre paletes. Identificou-se em tais situações problemas associados principalmente aos esforços na região lombar do operador. Este problema foi eliminado, no caso de tais bags, com a eliminação de desníveis no piso.

Para além das verificações pontuais, constata-se que a AET pode trazer oportunidades importantes se implementada longitudinalmente e com os devidos cuidados de observação, diálogo e análise das operações, ainda que não exista um limite claro entre o trabalho prescrito e o trabalho real. Não obstante, foi possível supor a partir do caso sob estudo que com os devidos cuidados é viável o desenvolvimento de uma 
AET, ainda não estejam claros os limites entre o trabalho prescrito e o trabalho real. Contudo, para isso, se faz necessário um cuidado redobrado por parte dos responsáveis pela implementação da AET no que compete ao seu papeis durante o desenvolvimento dela.

\section{REFERÊNCIAS}

ABIA - Associação Brasileira das Indústrias da Alimentação. Disponível em: http://www.abia.org.br. Acesso em: abr. 2018.

AEPS - Anuário estatístico da previdência social. Disponível em: http://sa.previdencia.gov.br/site/2015/08/AEPS-2015-FINAL.pdf. Acesso em: 17 out. 2018.

BATALHA, A. Identificação de perigos e avaliação de riscos: João Vaz das Neves, Lda. Instituto Politécnico de Setúbal, Escola Superior de Tecnologia de Setúbal, Setúbal, 2012.

BRASIL. Ministério do Trabalho e Emprego. Portaria 197, de 17 de dezembro de 2010. NR12 - Segurança no trabalho em máquinas e equipamentos. Brasília, DF, 24 dez. 2010.

BRASIL. Ministério do Trabalho e Emprego. Portaria 3.751, de 23 de novembro de 1990. NR7 - Ergonomia. Brasília, DF, 26 nov, 1990.

BRASIL. Secretaria de Vigilância Sanitária do Ministério da Saúde. Portaria no 326, de 30 de julho de 1997. Regulamento técnico sobre condições higiênico-sanitárias e de boas práticas de fabricação para estabelecimentos produtores/ industrializadores de alimentos. Diário Oficial da República Federativa do Brasil, Brasília, DF, 30 jul. 1997.

CASTRO, T.; OKAWA, C. Auditoria de Segurança e Saúde do Trabalho em uma Indústria de Alimentos do Estado do Paraná. Revista Produção Online, Florianópolis, SC, v. 16, n. 2, p. 678-704, 2016. https://doi.org/10.14488/1676-1901.v16i2.2063

COELHO, M. Análise Ergonômica do trabalho: aplicação em uma empresa de médio porte em Manaus-AM. Revista GEPROS, Gestão da Produção, Operações e Sistemas, Bauru, Ano 8, n. 4, p. 61-75, 2014.

CORRÊA, V.; BOLETTI, R. Ergonomia. 1. ed. Rio Grande do Sul: Bookman, 2015.

COSTA, M.; BRAGA, M. Segurança do trabalho na indústria de alimentos: a sinalização como aspecto fundamental. Revista Brasileira de Agrotecnologia, v. 5, n. 1, p. 58-63, 2015.

CTC - Centro de tecnologia canavieira. Manual de controle químico da falsificação de açúcar. Capítulo 2. Piracicaba, 2011.

DEIMLING, M.; PESAMOSCA, D. Análise ergonômica do trabalho em uma empresa de confecções. Revista Iberoamericana de Engenharia Industrial, Florianópolis, SC, Brasil, v. 6, n. 11, p. 37-58, 2014. https://doi.org/10.13084/2175-8018/ijie.v6n11p37-58

FERREIRA, L. Sobre a análise ergonômica do trabalho ou AET. Revista Brasileira de Saúde Ocupacional, São Paulo, 2015. https://doi.org/10.1590/0303-7657ED0213115 
Guérin, F., Laville, A., Daniellou, F., Durrafourg, J., Kerguellen, A. Compreender o trabalho para transformá-lo: a prática da ergonomia. São Paulo: Editora Edgard Blücher, 2001.

IIDA, I. Ergonomia: projeto e produção. 3. ed. rev. e ampl. São Paulo: Edgard Blucher, 2016.

MCATAMNEY, L.; CORLETT, E. N. RULA: a survey method for the. investigation of worldrelated upper limb disorders. Applied Ergonomics, v. 24, n. 2, p. 91-99, 1993. Disponível em: http://ftp.demec.ufpr.br/disciplinas/TM802/RULA original 1993.pdf. Acesso em: 23/06/2017.

MONTEIRO, M. Importância da ergonomia na saúde dos funcionários de unidade de alimentação e nutrição. Revista Baiana, BH, v. 33, n. 3, 2010.

MOORE, J.; GARG, A. The Strain Index: a proposed method to analyze jobs for risk of distal upper extremity disorders. Am. Ind. Hyg. Assoc. J., v. 56, p. 443-456, 1995.

https://doi.org/10.1202/0002-8894(1995)056<0443:TSIAPM>2.0.CO;2

MORAES, M. Princípios Ergonômicos. 1. ed. São Paulo: Saraiva, 2014.

RODRIGUES, L.; SANTANA, N.; BONOMO, R.; SILVA, L. Apreciação ergonômica do processo de produção de queijos em indústrias de laticínios. Revista Produção online, Florianópolis, SC, v.8, n.1, 2008. https://doi.org/10.14488/1676-1901.v8i1.29

SANTOS, N.; FIALHO, F. Manual de análise ergonômica do trabalho. 2. ed. Curitiba: Genesis, 1997.

SATO, L.; LACAZ, F. Cadernos de saúde do trabalhador: condições de trabalho e saúde dos trabalhadores(as) do ramo da alimentação. São Paulo, 2000.

SESI. Segurança e saúde para trabalhadores da indústria da alimentação. Brasília, 2008.

VICENZI, M.; PEREZ, Â.; GUERROUE, J. Análise de risco para segurança de alimentos: Dificuldades e Desafios de Fiscalização de Bebidas. Revista de Política Agrícola, Brasília, DF, n. 3, 2012.

WATERS, T; VERN P.; GARG A. Applications manual for the revised NIOSH lifting equation. Springfield, VA: U.S., Dept. of Health and Human Services, Public Health Service, Centers for Disease Control and Prevention, National Institute for Occupational Safety and Health, Division of Biomedical and Behavioral Science, for public sale by U.S. Dept. of Commerce, 1994.

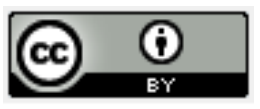

Artigo recebido em: 03/12/2018 e aceito para publicação em: 01/12/2019 DOI: http://dx.doi.org/10.14488/1676-1901.v19i4.3485 